Article

\title{
Gluten Contamination in Naturally or Labeled Gluten-Free Products Marketed in Italy
}

\author{
Anil K. Verma ${ }^{1, *}$, Simona Gatti ${ }^{1,2}$, Tiziana Galeazzi ${ }^{1}$, Chiara Monachesi ${ }^{1}$, Lucia Padella ${ }^{1}$, \\ Giada Del Baldo ${ }^{2}$, Roberta Annibali ${ }^{2}$, Elena Lionetti ${ }^{1,2}$ and Carlo Catassi ${ }^{1,2}$ \\ 1 Celiac Disease Research Laboratory, Department of Pediatrics, Università Politecnica delle Marche, \\ 60123 Ancona, Italy; simona.gatti@hotmail.it (S.G.); t.galeazzi@univpm.it (T.G.); \\ chiara.monachesi28@gmail.com (C.M.); luciapadella@libero.it (L.P.); \\ mariaelenalionetti@gmail.com (E.L.); c.catassi@univpm.it (C.C.) \\ 2 Department of Pediatrics, Università Politecnica delle Marche, 60123 Ancona, Italy; \\ giadadelbaldo@gmail.com (G.D.B.); robertannibali@hotmail.it (R.A.) \\ * Correspondence: anilkrvermaa@gmail.com or a.k.verma@pm.univpm.it; \\ Tel.: +39-071-596-28-34; Fax: +39-071-36281
}

Received: 14 December 2016; Accepted: 3 February 2017; Published: 7 February 2017

\begin{abstract}
Background: A strict and lifelong gluten-free diet is the only treatment of celiac disease. Gluten contamination has been frequently reported in nominally gluten-free products. The aim of this study was to test the level of gluten contamination in gluten-free products currently available in the Italian market. Method: A total of 200 commercially available gluten-free products (including both naturally and certified gluten-free products) were randomly collected from different Italian supermarkets. The gluten content was determined by the R5 ELISA Kit approved by EU regulations. Results: Gluten level was lower than 10 part per million (ppm) in 173 products $(86.5 \%)$, between 10 and $20 \mathrm{ppm}$ in $9(4.5 \%)$, and higher than $20 \mathrm{ppm}$ in $18(9 \%)$, respectively. In contaminated foodstuff (gluten $>20 \mathrm{ppm}$ ) the amount of gluten was almost exclusively in the range of a very low gluten content. Contaminated products most commonly belonged to oats-, buckwheat-, and lentils-based items. Certified and higher cost gluten-free products were less commonly contaminated by gluten. Conclusion: Gluten contamination in either naturally or labeled gluten-free products marketed in Italy is nowadays uncommon and usually mild on a quantitative basis. A program of systematic sampling of gluten-free food is needed to promptly disclose at-risk products.
\end{abstract}

Keywords: celiac disease; gluten-free products; naturally gluten-free; R5 ELISA; oats; buckwheat; lentils

\section{Introduction}

Celiac disease (CD) is an autoimmune condition characterized by permanent intolerance to dietary gluten, a protein complex found in wheat, rye and barley, occurring in genetically predisposed individuals [1]. The hallmarks of active CD are the presence of serum autoantibodies (e.g., IgA antitransglutaminase and antiendomysial antibodies) and a small intestinal enteropathy characterized, in typical cases, by villous atrophy, crypt hypertrophy and increased number of intraepithelial lymphocytes (IELs). Treatment of CD is based on the lifelong exclusion of gluten-containing food from the diet. The gluten-free diet (GFD) determines the gradual disappearance of symptoms and serum autoantibodies, and the normalization of the intestinal histological architecture [2].

Unfortunately, $C D$ patients are highly sensitive to the toxic effect of gluten. It has been shown that the protracted ingestion of traces of gluten (10-50 $\mathrm{mg}$ on a daily basis) may damage the integrity of the small intestinal mucosa, an increased number of IELs being the first marker of mucosal deterioration [3]. By combining these toxicity data with the observed food intake, it has been calculated that gluten-free 
products with less than $20 \mathrm{mg} / \mathrm{kg}$ (or parts per million = ppm) of gluten contamination are safe over a wide range of daily consumption [4]. The $20 \mathrm{ppm}$ threshold for gluten-free food has been endorsed by the Codex Alimentarius [5] and other agencies, e.g., the US Food and Drug Administration (FDA) and the European Food Safety Authority (EFSA) [6].

Despite the availability of a wide range of natural (by origin) and industrially-prepared gluten-free food, complete avoidance of gluten from the diet is difficult to maintain. Gluten is indeed a "pervasive" nutrient that may contaminate otherwise gluten-free items along the production chain, from the field to the milling, stockage and manufacture steps [7]. Furthermore wheat flour or purified gluten are largely added by the food industry to naturally gluten-free food, due to its technological properties, particularly the high visco-elasticity. Protracted intake of items contaminated with gluten traces may cause persistent intestinal damage and symptoms in treated $C D$ patients [8].

The scarcity of published data on the possible gluten contamination of nominally gluten-free products is a matter of concern. This is the reason why we decided to undertake the current study, by measuring gluten in a large sample of gluten-free products that are currently on the market in Italy, using the only method (R5 ELISA) approved by the EU regulation. We present here the final results of these analyses on 200 commercially available gluten-free products.

\section{Materials and Methods}

\subsection{Collection of Food Products}

A sampling plan was developed to analyze gluten-free products, including substitutes of wheat-based food, and other starch-rich food, e.g., legumes, that are extensively used in day-to-day meal preparation by individuals following a gluten-free diet. Selected products included different brands of (a) gluten-free flour, pasta, snacks, cookies, muesli, breakfast cereals, bread, and pizza; (b) rice, oats, buckwheat, quinoa, amaranth, mixed cereals, lentils, and chickpeas. Between April and October 2016, a total of 200 commercially available food products of common use were purchased in randomly chosen supermarkets in Ancona, Italy.

Food products were carefully identified and categorized into two broad categories, i.e., naturally (by origin) gluten-free products (Group 1) and labeled "gluten-free" products (Group 2). Group 1 was further divided into 1a, reporting no information of gluten content (defined herein as "products with unknown gluten content"), and 1b, reporting "may contain traces of gluten" on the label. Group 2, i.e., certified gluten-free products, were categorized as $2 \mathrm{a}$, including products fulfilling the EU regulation for gluten-free products (UE 828/2014) plus the quality certification released by the Italian Celiac Society (identified by the "Crossed Ear" symbol on the package) or $2 b$, including gluten-free products fulfilling the EU regulation for gluten-free products only (Figure 1).

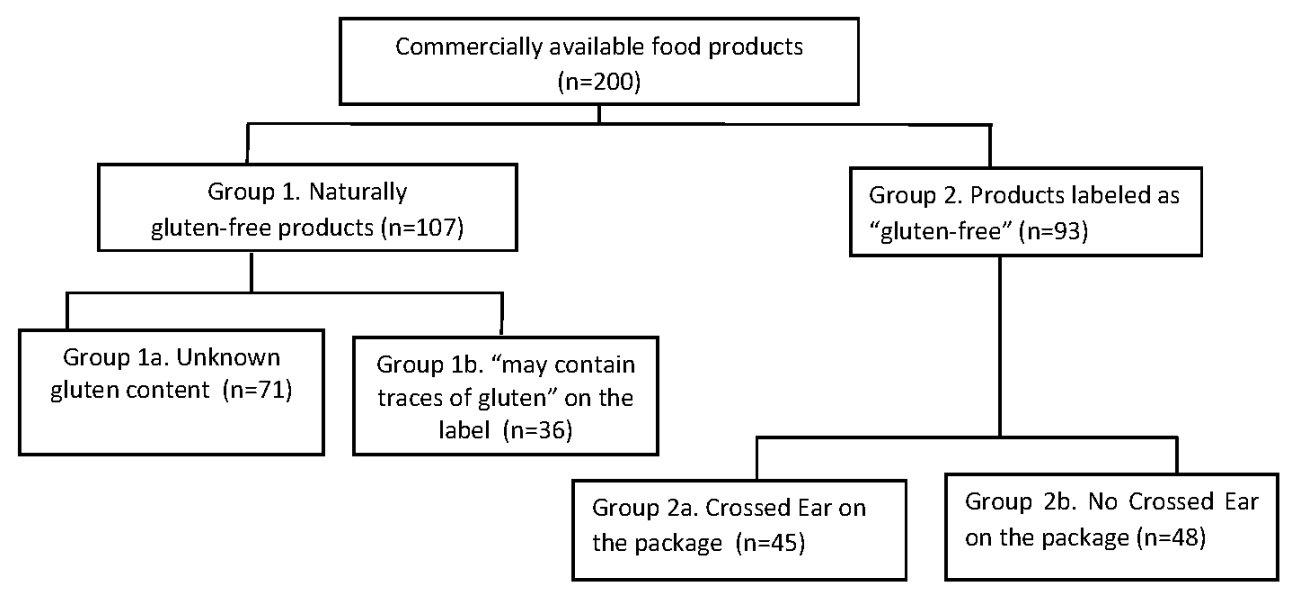

Figure 1. Types of food products analyzed in this study. 


\subsection{Determination of Gluten Content}

All food products were subjected to gluten content determination by the Ridascreen Gliadin sandwich R5 enzyme-linked immunosorbent assay R-7001 (R-Biopharm, Darmstadt, Germany) at the Celiac Disease Research Laboratory of the Department of Pediatrics, Università Politecnica delle Marche, Ancona, Italy. During each run of ELISA, manufacturer's guidelines were strictly followed. Briefly, the steps of the ELISA procedure were as follows.

\subsubsection{Extraction and Preparation of Samples}

All samples were given a unique laboratory code and their details (including brand, cost, ingredient, food type, etc.) were recorded on an Excel sheet. Five grams of each sample were homogenized and crushed in a laboratory blender (solid food products). Each time after the crushing of a particular sample, parts of the blender were removed and washed with alkaline-enzyme detergent and rinse with $70 \%$ ethanol and dried before processing of another sample. Homogenized samples were stored in sterile tubes. Ridascreen R-7006 cocktail solution, containing detergents and reducing agent, was used for the extraction of samples. One-quarter gram of processed solid samples and $0.25 \mathrm{~mL}$ of liquid samples were measured in separate pre-labeled falcon tubes. In tannin and polyphenol containing products additionally $0.25 \mathrm{~g}$ of skimmed milk powder was added. After this preparation, $2.5 \mathrm{~mL}$ of cocktail solution was added in each tube under a chemical hood and tubes were vortexed and kept in water bath at $50{ }^{\circ} \mathrm{C}$ for $40 \mathrm{~min}$. After the incubation, tubes were allowed to maintain room temperature and $7.5 \mathrm{~mL}$ of freshly prepared $80 \%$ ethanol was mixed in each tube and kept on a shaker for $1 \mathrm{~h}$. Samples were then transferred into $1.5 \mathrm{~mL}$ of Eppendorf tubes and centrifuged at least $2500 \mathrm{~g}$ for $10 \mathrm{~min}$, supernatant was separated and collected into another $1.5 \mathrm{~mL}$ Eppendorf tube and stored at room temperature. To avoid any possible cross contamination, samples were crushed in different rooms and at different time intervals.

\subsubsection{Gluten Quantification}

Extracted food samples were diluted at 1:12.5 in provided sample dilution, standard and samples were added in duplicate into pre-defined ELISA wells and enzyme conjugate was added to each well followed by wash of ELISA plate by washing buffer and kept for incubation for $30 \mathrm{~min}$ at room temperature. Substrate and chromogen were added and the reaction was stopped by provided stop solution and reading was obtained at the absorbance of $450 \mathrm{~nm}$. Samples that showed an absorption value above the highest standard value were further diluted to get the absorption value within the range. The lower limit of the quantification was $2.5 \mathrm{ppm}(\mathrm{mg} / \mathrm{kg})$ of gliadin, corresponding to $5 \mathrm{ppm}(\mathrm{mg} / \mathrm{kg})$ of gluten. Results were calculated by the suggested method and then entered in the Excel sheet.

Food products containing gluten level lower than $20 \mathrm{ppm}$ were considered as gluten-free while products with gluten level between 20 and $100 \mathrm{ppm}$ were classified as products with low gluten contamination and products with more than $100 \mathrm{ppm}$ of gluten were considered significantly contaminated. All products with a gluten level higher than $20 \mathrm{ppm}$ were re-extracted and analyzed second time.

\subsection{Quality Control}

Each time absorption value of ELISA standards was assured with the quality assurance certificate provided with the ELISA kit. The result of each run was discussed with research group members and random results were sent to the principal company for expert comments and suggestion. At different time intervals, all the group members gathered and discussed the procedure and further action.

\subsection{Cost Analysis: Correlation between the Cost of the Product and Gluten Contamination}

If at least 5 products with similar ingredients from different brands were available, the mean price was calculated. Then, for each product the price index (PI) was calculated as the product price divided 
by the mean price of the category. The PI was then categorized in 3 groups (price categories): PI $<0.75$ (products with a low price), PI: $0.75-1.25$ (products with an average price), PI $>1.25$ (products with a high price).

\subsection{Statistics}

Data are presented as proportions, means and S.D., medians and range, as appropriate. The Kruskal-Wallis one-way analysis of variance was used to determine if there was statistically significant difference of gluten contamination between the four groups of products ( $1 a, 1 b, 2 a$, and $2 b$ ), and, if significant, post hoc test was used for multiple comparisons. Comparison between proportions of contaminated ( $>20 \mathrm{ppm})$ and not contaminated ( $<20 \mathrm{ppm})$ samples within each group was calculated by the Fisher's test. Spearman's test was used to correlate quantitative variables (prices and gluten levels). Results were found significant when $p<0.05$. The statistical analysis was performed using the Software Program Stata System (SPSS) v17.0 (Chicago, IL, USA).

\section{Results}

\section{Detection of Gluten Contamination}

Overall, 200 food products were analyzed: 107 in Group 1 (group 1a, $n=71$; group 1b, $n=36$ ) and 93 in Group B (group 2a, $n=45$; group 2b, $n=48$ ). Overall $173(86.5 \%)$ products were detected with gluten level lower than $10 \mathrm{ppm}$, nine (4.5\%) products contained between 10 and $20 \mathrm{ppm}$ of gluten, and $18(9 \%)$ products were detected with gluten level above the maximum tolerable of $20 \mathrm{ppm}$ (15 products containing less and three products more than $100 \mathrm{ppm}$ of gluten) (Table 1).

The proportion of contaminated products (gluten $>20 \mathrm{ppm}$ ) according to the staple ingredient and to the food category is reported in Tables 2 and 3, respectively. In products belonging to group 1,16 items $(8 \%)$ were contaminated with more than $20 \mathrm{ppm}$ of gluten, $12(6 \%)$ from sub-group $1 \mathrm{a}$ (gluten content unknown) and four ( $2 \%$ ) products from sub-group $1 \mathrm{~b}$ ("may contain gluten") products. In group 2 (products labeled as gluten free), only two (1\%) products were found to have gluten level higher than $20 \mathrm{ppm}$. These products belonged to subgroup $2 \mathrm{~b}$, whereas no "Crossed-Ear" product was found to contain gluten at 20 or more ppm (Figure 2). Overall, we found a significant different proportion of contamination between the four groups of products (Kruskal-Wallis, $p<0.01$ ). By multiple comparison, a significant higher proportion of contaminated products was found in group la as compared to group $2 \mathrm{a}(16 \%$ vs. $0, p<0.01)$ (Table 2$)$. No significant difference was found in the proportion of contaminated products between groups $1 \mathrm{a}$ and $1 \mathrm{~b}$ and between groups $2 \mathrm{a}$ and $2 \mathrm{~b}$, respectively (Table 2, Figure 3). By comparing the staple ingredients, we found a significant higher proportion of contaminated products in oats, buckwheat and lentils as compared to chickpeas, corn, mixed seeds, quinoa, and chocolate. By comparing the food categories, the lunch/dinner products were significantly more contaminated as compared to snacks.

Overall 53 products belonging to six different food categories (lentils, chickpeas, beans, oats, buckwheat and quinoa) were considered for the cost analysis. The PI was not significantly correlated to the content of gluten $(r=-0.009 ; p=0.51)$. However, a significantly different distribution of price categories was found according to the level of gluten contamination. As shown in Figure 4, a higher proportion of low price foods were found in products with levels of gluten $>20 \mathrm{ppm}(p<0.01)$.

Table 1. Level of gluten contamination in the 200 examined products.

\begin{tabular}{cccc}
\hline Gluten Content (ppm) & Number of Products & Median (Range) (ppm) & Mean \pm SD (ppm) \\
\hline$<10$ & 173 & $<5(<0.5-9.3)$ & n.a. \\
$10-20$ & 9 & $13.9(10.4-17.1)$ & $14.1 \pm 2.2$ \\
$>20$ & 18 & $31.7(20.4-126.2)$ & $49.2 \pm 35.9$ \\
\hline
\end{tabular}

n.a. $=$ not applicable (due to the $(<5)$ values). 


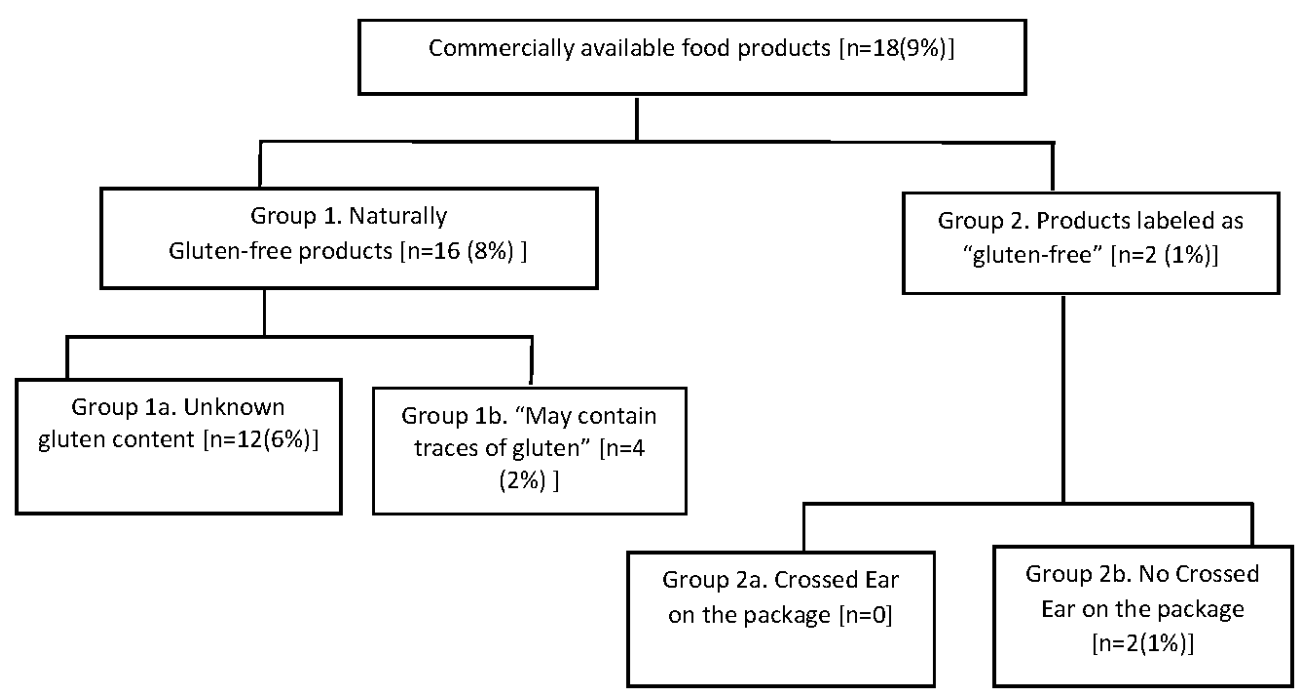

Figure 2. Number of food products containing gluten $>20 \mathrm{ppm}$ in different groups.

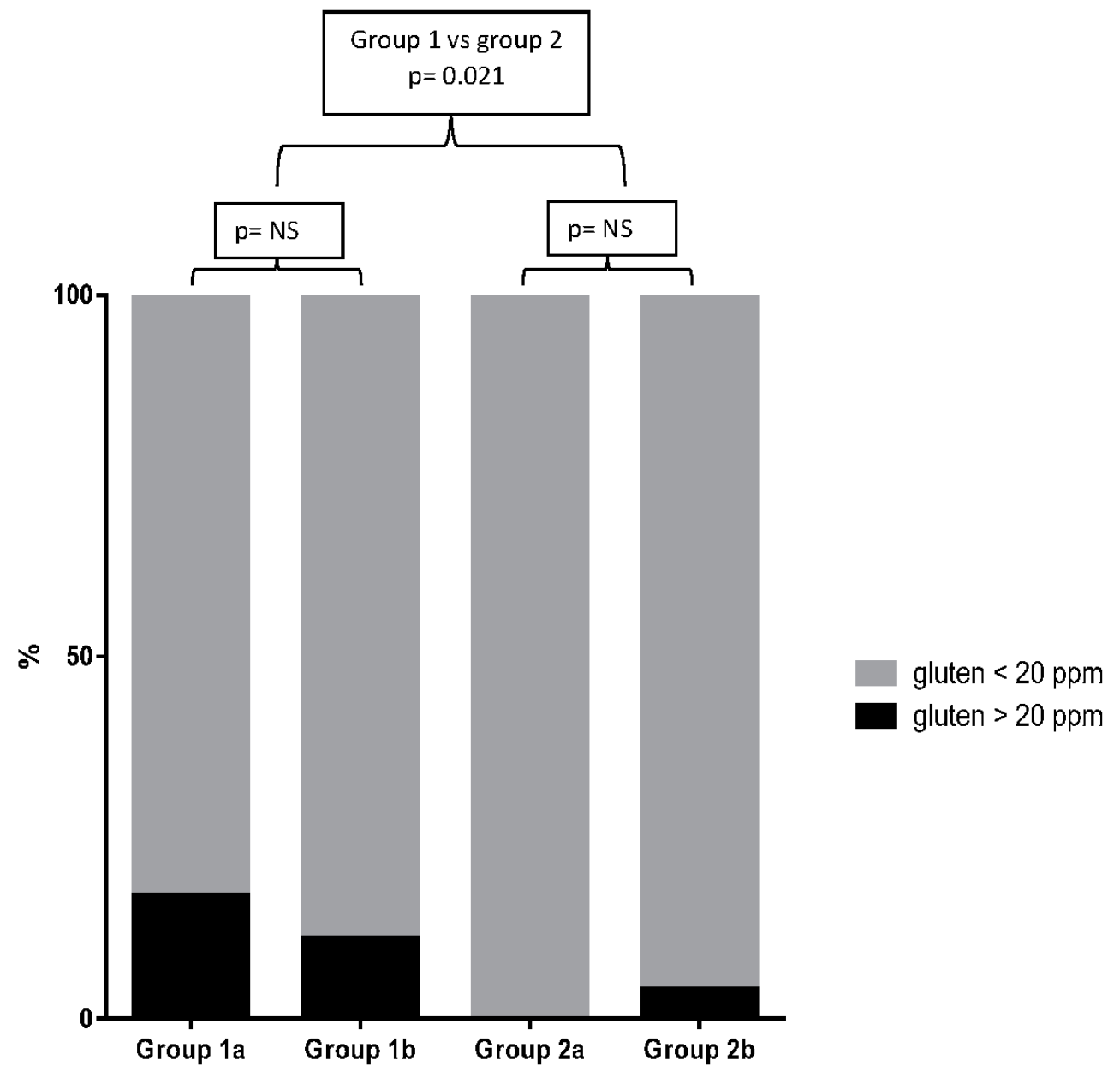

Figure 3. Percentage of contaminated products in each food group. 
Table 2. Proportion of items containing $>20 \mathrm{ppm}$ of gluten by staple ingredient (contaminated/ tested products).

\begin{tabular}{|c|c|c|c|c|c|c|c|}
\hline \multirow{3}{*}{ Item } & \multirow{3}{*}{ Overall * } & \multirow{2}{*}{\multicolumn{2}{|c|}{$\begin{array}{c}\text { Group 1 } \\
\text { Naturally Gluten } \\
\text { Free Products }\end{array}$}} & \multirow{2}{*}{\multicolumn{2}{|c|}{$\begin{array}{c}\text { Group 2 } \\
\begin{array}{c}\text { Products Labeled as } \\
\text { "Gluten Free" }\end{array}\end{array}$}} & \multirow[b]{2}{*}{$p$} & \multirow[b]{2}{*}{$p$} \\
\hline & & & & & & & \\
\hline & & Group 1a & Group 1b & Group 2a & Group 2b & Kruskal-Wallis & Multiple Comparisons \\
\hline Amaranth & $0 / 2$ & $0 / 1$ & $0 / 1$ & - & - & 1.000 & \\
\hline Buckwheat & $5 / 12$ & $3 / 5$ & $1 / 3$ & $0 / 1$ & $1 / 3$ & 0.695 & \\
\hline Chickpeas & $0 / 6$ & $0 / 4$ & $0 / 2$ & - & - & 1.000 & \\
\hline Chocolate & $0 / 9$ & $0 / 1$ & $0 / 3$ & - & $0 / 5$ & 1.000 & \\
\hline Coconut & $1 / 3$ & $1 / 2$ & - & - & $0 / 1$ & 0.480 & \\
\hline Corn & $0 / 40$ & $0 / 8$ & $0 / 5$ & $0 / 23$ & $0 / 4$ & 1.000 & \\
\hline Dry fruit & $0 / 2$ & $0 / 2$ & - & - & - & - & \\
\hline Fruit Candy & $0 / 4$ & $0 / 1$ & - & - & $0 / 3$ & 1.000 & \\
\hline Fruit Jam & $0 / 4$ & $0 / 2$ & - & - & $0 / 2$ & 1.000 & \\
\hline Kidney Bean & $0 / 7$ & $0 / 5$ & $0 / 2$ & - & - & 1.000 & \\
\hline Lentil & $4 / 17$ & $2 / 6$ & $2 / 11$ & - & - & 0.495 & \\
\hline Mixed Cereal & $1 / 25$ & $0 / 2$ & $0 / 2$ & $0 / 10$ & $1 / 11$ & 0.736 & \\
\hline Mixed Seeds & $0 / 12$ & $0 / 8$ & $0 / 1$ & $0 / 1$ & $0 / 2$ & 1.000 & \\
\hline Oats & $4 / 5$ & $4 / 5$ & - & - & - & - & \\
\hline Others & $1 / 14$ & $0 / 4$ & $1 / 3$ & - & $0 / 7$ & 0.160 & \\
\hline Peanuts & $1 / 4$ & $1 / 4$ & - & - & - & - & \\
\hline Quinoa & $0 / 10$ & $0 / 5$ & $0 / 1$ & $0 / 1$ & $0 / 3$ & 1.000 & \\
\hline Rice & $1 / 24$ & $1 / 6$ & $0 / 2$ & $0 / 9$ & $0 / 7$ & 0.392 & \\
\hline Total & $18 / 200$ & $12 / 71$ & $4 / 36$ & $0 / 45$ & $2 / 48$ & 0.010 & 1a vs. 2a $p=0.012$ \\
\hline
\end{tabular}

${ }^{*}$ Kruskal-Wallis $p<0.001$; Multiple comparisons: $p<0.001$ : mixed seeds vs. oats, quinoa vs. oats, chocolate vs. oats, corn vs. oats; $p=0.001$ : chickpeas vs. oats; $p=0.002$ : corn vs. buckwheat.

Table 3. Proportion of items containing $>20 \mathrm{ppm}$ of gluten by food category (contaminated/ tested products).

\begin{tabular}{|c|c|c|c|c|c|c|c|}
\hline \multirow[b]{2}{*}{ Food Category } & \multirow[b]{2}{*}{ Overall * } & \multirow{2}{*}{\multicolumn{2}{|c|}{$\begin{array}{c}\text { Group } 1 \\
\text { Naturally Gluten } \\
\text { Free Products } \\
\end{array}$}} & \multirow{2}{*}{\multicolumn{2}{|c|}{$\begin{array}{c}\text { Group 2 } \\
\begin{array}{c}\text { Products Labeled as } \\
\text { "Gluten Free" }\end{array}\end{array}$}} & \multirow[b]{2}{*}{$p$} & \multirow[b]{2}{*}{$p$} \\
\hline & & & & & & & \\
\hline Breakfast & $0 / 11$ & $0 / 4$ & $0 / 1$ & $0 / 4$ & $0 / 2$ & 1.000 & \\
\hline Lunch/dinner & $15 / 88$ & $10 / 45$ & $4 / 25$ & $0 / 12$ & $1 / 6$ & 0.348 & \\
\hline Pizza & $1 / 3$ & - & - & - & $1 / 3$ & - & \\
\hline Total & $18 / 200$ & $12 / 71$ & $4 / 36$ & $0 / 45$ & $2 / 48$ & 0.010 & 1a vs. $2 \mathrm{a} p=0.012$ \\
\hline
\end{tabular}

${ }^{*}$ Kruskal-Wallis $p=0.004$; Multiple comparisons: Lunch/dinner versus snacks: $p=0.006$.

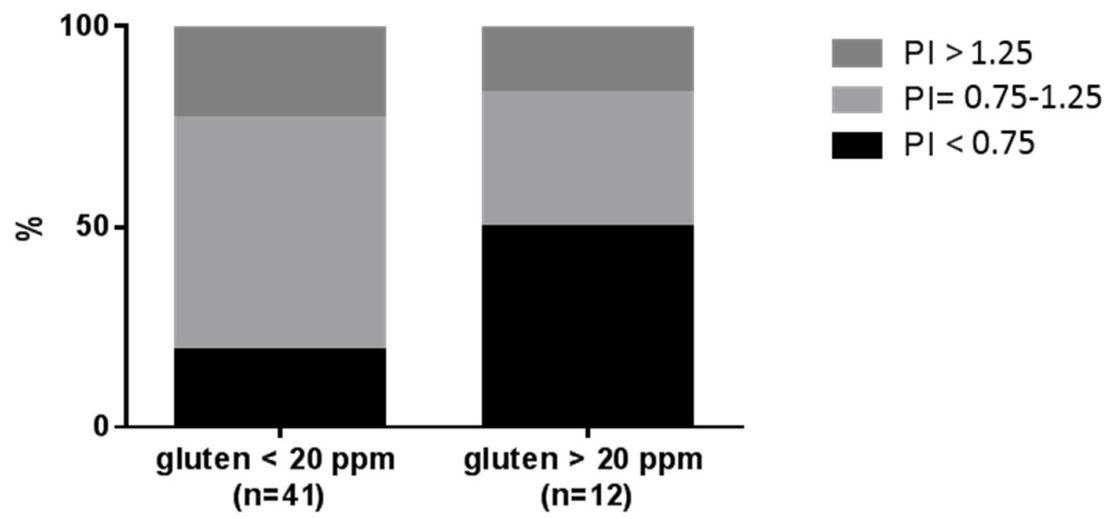

Figure 4. Distribution of price indexes (PIs) according to the level of gluten contamination. 


\section{Discussion}

Our large survey shows that gluten contamination is low in gluten-free food marketed in Italy, both in terms of the percentage of contaminated products $(9 \%)$, and the amount of gluten in contaminated products (almost exclusively in the range of the low gluten content 20-100 ppm). However, naturally (by origin) gluten-free products are at significantly higher risk of contamination as compared to products certified as gluten-free; indeed, we found that $16 \%$ of naturally gluten-free products with unknown gluten content are contaminated with respect to none of the certified gluten-free products with the crossed-ear symbol. Of note, among the certified gluten-free products without crossed-ear symbol we found that two out of $48(4 \%)$ were contaminated with respect to none of the products with crossed-ear symbol; although this difference is not significant, it may suggest that the more stringent controls performed on "Crossed Ear" gluten-free products guarantee less risk of gluten contamination.

Our findings are more encouraging than previous studies in some American countries, e.g., contamination was found in $20.5 \%$ of gluten-free products marketed in the USA [7] and $21.5 \%$ in Brazil [9] respectively, and are in line with previous data from Canada [10] and Europe [4]. Compared to the past, the picture has clearly improved, most likely due to the worldwide implementation of the 20 ppm maximum threshold of gluten contamination established by the Codex Alimentarius in the year 2008 [5]. Based on these data and the dietary habits of the Italian population, the safety threshold of 10-50 mg of daily gluten would hardly be exceeded even by CD patients consuming very large quantities of gluten-free items (provided that no other contaminated food is eaten at the same time).

Quantification of gluten in food is difficult, for several reasons. Firstly gluten is not a single protein but a mix of different protein components (microheterogeneity) generally classified as gliadins, glutenins, globulins and albumins [11]. Measuring all these different fractions is clearly unpractical. Gliadins are the major component on a quantitative basis, and it is generally assumed that the ratio between gliadins (the fraction that is measured with the R5 test) and overall gluten is 1:2 $(50 \%)[12,13]$. Other analytical problems include the difficulty in (a) specifically quantifying all the different celiac-toxic peptides contained in gluten; (b) extracting gluten from the different food matrixes; and (c) measuring hydrolysed gluten peptides (e.g., in fermented food such as beer). Several tools have been developed for gluten quantification in food, such as the R5, the G12 and the $\alpha-20$ antibody-based ELISA kits [14,15]. In the present study we used the R5 method, an ELISA test based on specially designed monoclonal antibodies raised against a pentapeptide from rye. It detects prolamins of wheat (gliadins), rye (secalins) and barley (hordeins), i.e., all the cereals that are toxic for celiac patients, in both raw (flours) and processed food products [16]. It is the only method certified by the Association of Officials Analytical Chemists (AOAC), and is considered as the method of choice for gluten detection in food, according to the Codex Alimentarius Commission and other International Agencies $[5,6]$. Most recent studies on gluten contamination have been performed using the same R5 test, a finding that allows comparisons among the results of different surveys $[4,7,9,10,17]$.

As reported in previous studies $[4,7,9,10,17]$, we found that products at significant higher risk of contamination of gluten are oats (four out of five examined items), buckwheat (5/12) and lentils-based $(4 / 17)$ products. Several studies have shown that medium-high amounts of gluten-uncontaminated oats can be safely ingested by patients with $\mathrm{CD}[18,19]$. Official recommendations acknowledge the safety of products containing purified oats, and several national associations for CD allow inclusion of oats in the diet of people with CD [19]. Unfortunately, the commercial oat supply is often contaminated with wheat. In Canada $88 \%$ of 133 oat samples were contaminated above 20 ppm [10]. There are possibilities for cross-contamination in the field, in the transport of the grain, in the storage of the grain, and in the milling and packaging facilities $[7,10]$. This is a deplorable situation since oats is rich in soluble dietary fiber, vitamins and minerals, and may unquestionably improve the nutritional value and increase the palatability of the GFD, while expanding food choices and ultimately improving the life quality of people with CD. Buckwheat is a gluten-free pseudocereal that belongs to the Polygonaceae family. Buckwheat grain is a highly nutritional food component that has been shown to provide a wide range of beneficial effects. Health benefits attributed to Buckwheat include plasma 
cholesterol level reduction, neuroprotection, anticancer, anti-inflammatory, antidiabetic effects, and improvement of hypertension. In addition, buckwheat has been reported to possess prebiotic and antioxidant activities [20]. The possible gluten contamination of buckwheat has been correlated with the high content of fiber [21]. The frequent gluten contamination of lentils was somewhat unexpected, since this food is a legume and not a cereal, and its production chain is far different from wheat. Lentils are an edible pulse that is part of the human diet since the Neolitic age, being one of the first crops domesticated in the Near East. Lentils are a rich source of numerous nutrients, including protein, starch, folate, thiamin, pantothenic acid, vitamin B6, phosphorus, iron and zinc [22]. The origin of gluten contamination of lentils remains unclear. Many patients or caregivers check lentils seed by seed, and have reported that rare wheat seeds can be found mixed with lentils, most likely due to contamination occurring in the field. The practice of inspecting and washing lentils before cooking should be recommended when the package does not report any gluten-free labeling.

It is important to underscore that oats, buckwheat and lentils are nutritious dietary components that may increase the variety of carbohydrate- and fiber-rich food in the gluten-free diet. For this reason, we hope that the food industry will pay more attention in ensuring and certifying a gluten-free food chain for these important ingredients.

Finally, in the present study we also aimed to evaluate if the gluten contamination is, to some extent, related to the cost of the product. It is worth noting that we found that a higher proportion of low price foods were contaminated with respect to higher price foods $(p<0.01)$, suggesting that the lower the price the lower the quality of control on the gluten contamination.

Despite the GFD, many treated CD patients frequently show incomplete resolution of the histological intestinal damage at the follow-up intestinal biopsy, suggesting ongoing gluten ingestion [8]. Since our data and other surveys [4] found that gluten contamination of wheat substitutes does not represent a big issue in recent years, this persistent enteropathy is probably related to different sources of contamination, such as voluntary dietary transgressions, particularly in adolescents, or contaminated meals consumed outside home. Consumption of food prepared away from home plays an increasingly large role in the diet. In the US in 1970, 25.9 percent of all food spending was on food away from home; by 2012, that share rose to its highest level of 43.1 percent (data of the US Department of Agriculture, 2016; www.ers.usda.gov). In restaurants, pizzerias and cafeterias the chance of getting gluten-contamined GF food is higher than home, due to inadequate personnel training, careless use of tools/workbench and so forth. An active policy of training and education on the requirements for the GFD should be addressed to employees at food services.

\section{Conclusions}

Gluten contamination in either naturally or commercial gluten-free products marketed in Italy is nowadays uncommon and usually mild on a quantitative basis. Crossed Ear and higher cost gluten-free products are in general safer than other products. Caution is however needed to interpret these findings, due to the intrinsic limitations of the analytical method for determining gluten traces in food matrixes. A program of systematic sampling of gluten-free food is needed to promptly disclose at-risk products, to ensure the safety of available products and ultimately improve the long-term wellbeing of individuals affected with $\mathrm{CD}$ or other gluten-related disorders.

Author Contributions: Anil K. Verma designed and performed the laboratory tests; Anil K. Verma, Simona Gatti, Giada Del Baldo; Tiziana Galeazzi and Roberta Annibali, acquired the data; Anil K. Verma and Carlo Catassi wrote and drafted the manuscript; Simona Gatti and Tiziana Galeazzi conceived and designed the experiments; Simona Gatti, Tiziana Galeazzi, Chiara Monachesi, Lucia Padella, Elena Lionetti and Carlo Catassi gave technical and material support; Tiziana Galeazzi supervised the laboratory experiments; Simona Gatti, Tiziana Galeazzi, Elena Lionetti and Carlo Catassi critically revised the manuscript; Elena Lionetti and Carlo Catassi analyzed and interpreted the data. Carlo Catassi designed the overall study concept and gave administrative and financial support and supervised the study. All authors revised and approved the final version.

Conflicts of Interest: Carlo Catassi has received consultancy funds from Schär. Other authors declare no conflict of interest. 


\section{References}

1. Fasano, A.; Catassi, C. Current approaches to diagnosis and treatment of celiac disease: An evolving spectrum. Gastroenterology 2001, 120, 636-651. [CrossRef] [PubMed]

2. Lionetti, E.; Castellaneta, S.; Francavilla, R.; Pulvirenti, A.; Tonutti, E.; Amarri, S.; Barbato, M.; Barbera, C.; Barera, G.; Bellantoni, A.; et al. Introduction of gluten, HLA status, and the risk of celiac disease in children. N. Engl. J. Med. 2014, 371, 1295-1303. [CrossRef] [PubMed]

3. Catassi, C.; Fabiani, E.; Iacono, G.; D'Agate, C.; Francavilla, R.; Biagi, F.; Volta, U.; Accomando, S.; Picarelli, A.; De Vitis, I.; et al. A prospective, double-blind, placebo-controlled trial to establish a safe gluten threshold for patients with celiac disease. Am. J. Clin. Nutr. 2007, 85, 160-166. [PubMed]

4. Gibert, A.; Kruizinga, A.G.; Neuhold, S.; Houben, G.F.; Canela, M.A.; Fasano, A.; Catassi, C. Might gluten traces in wheat substitutes pose a risk in patients with celiac disease? A population-based probabilistic approach to risk estimation. Am. J. Clin. Nutr. 2013, 97, 109-116. [CrossRef] [PubMed]

5. Codex Alimentarius Commission. Foods for Special Dietary Use for Persons Intolerant to Gluten Codex STAN 118-1979; Codex Alimentarius Commission: Rome, Italy, 2008.

6. European Commission, COMMISSION REGULATION No 41/2009 of 20 January 2009 Concerning the Composition and Labelling of Foodstuffs Suitable for People Intolerant to Gluten. 2009. Available online: http:/ / eur-lex.europa.eu/LexUriServ/LexUriServ.do?uri=OJ:L:2009:016:0003:0005:EN:PDF (accessed on 14 December 2015).

7. Lee, H.J.; Anderson, Z.; Ryu, D. Gluten contamination in foods labeled as "gluten free" in the United States. J. Food Prot. 2014, 77, 1830-1833. [CrossRef] [PubMed]

8. Lanzini, A.; Lanzarotto, F.; Villanacci, V.; Mora, A.; Bertolazzi, S.; Turini, D.; Carella, G.; Malagoli, A.; Ferrante, G.; Cesana, B.M.; et al. Complete recovery of intestinal mucosa occurs very rarely in adult coeliac patients despite adherence to gluten-free diet. Aliment. Pharmacol. Ther. 2009, 15, 1299-1308. [CrossRef] [PubMed]

9. Farage, P.; de Medeiros Nóbrega, Y.K.; Pratesi, R.; Gandolfi, L.; Assunção, P.; Zandonadi, R.P. Gluten contamination in gluten-free bakery products: A risk for coeliac disease patients. Public Health Nutr. 2016, 15, 1-4. [CrossRef] [PubMed]

10. Koerner, T.B.; Cléroux, C.; Poirier, C.; Cantin, I.; Alimkulov, A.; Elamparo, H. Gluten contamination in the Canadian commercial oat supply. Food Addit. Contam. Part A Chem. Anal. Control Expo. Risk Assess. 2011, 28, 705-710. [CrossRef] [PubMed]

11. Zilić, S.; Barać, M.; Pešić, M.; Dodig, D.; Ignjatović-Micić, D. Characterization of proteins from grain of different bread and durum wheat genotypes. Int. J. Mol. Sci. 2011, 12, 5878-5894.

12. Wieser, H.; Antes, S.; Seilmeier, W. Quantitative determination of gluten protein types in Wheat flour by reversed-phase high-performance liquid chromatography. Cereal Chem. 1998, 75, 644-650. [CrossRef]

13. Haas-Lauterbach, S.; Immer, U.; Richter, M.; Koehler, P. Gluten fragment detection with a competitive ELISA. J. AOAC Int. 2012, 5, 377-381. [CrossRef]

14. Halbmayr-Jech, E.; Hammer, E.; Fielder, R.; Coutts, J.; Rogers, A.; Cornish, M. Characterization of G12 sandwich ELISA, a next-generation immunoassay for gluten toxicity. J. AOAC Int. 2012, 95, 372-376. [CrossRef] [PubMed]

15. Mujico, J.R.; Dekking, L.; Kooy-Winkelaar, Y.; Verheijen, R.; van Wichen, P.; Streppel, L.; Sajic, N.; Drijfhout, J.W.; Koning, F. Validation of a new enzyme-linked immunosorbent assay to detect the triggering proteins and peptides for celiac disease: interlaboratory study. J. AOAC Int. 2012, 95, 206-215. [CrossRef] [PubMed]

16. Valdés, I.; García, E.; Llorente, M.; Méndez, E. Innovative approach to low-level gluten determination in foods using a novel sandwich enzyme-linked immunosorbent assay protocol. Eur. J. Gastroenterol. Hepatol. 2003, 15, 465-474. [CrossRef] [PubMed]

17. Koerner, T.B.; Cleroux, C.; Poirier, C.; Cantin, I.; La Vieille, S.; Hayward, S.; Dubois, S. Gluten contamination of naturally gluten-free flours and starches used by Canadians with celiac disease. Food Addit. Contam. Part A Chem. Anal. Control Expo. Risk Assess. 2013, 30, 2017-2021. [CrossRef] [PubMed]

18. La Vieille, S.; Pulido, O.M.; Abbott, M.; Koerner, T.B.; Godefroy, S. Celiac Disease and Gluten-Free Oats: A Canadian Position Based on a Literature Review. Can. J. Gastroenterol. Hepatol. 2016, 2016, 1870305. [CrossRef] [PubMed] 
19. Gatti, S.; Caporelli, N.; Galeazzi, T.; Francavilla, R.; Barbato, M.; Roggero, P.; Malamisura, B.; Iacono, G.; Budelli, A.; Gesuita, R.; et al. Oats in the Diet of Children with Celiac Disease: Preliminary Results of a Double-Blind, Randomized, Placebo-Controlled Multicenter Italian Study. Nutrients 2013, 5, 4653-4664. [CrossRef] [PubMed]

20. Giménez-Bastida, J.A.; Zieliński, H. Buckwheat as a Functional Food and Its Effects on Health. J. Agric. Food Chem. 2015, 63, 7896-7913. [CrossRef] [PubMed]

21. La Vieille, S.L.; Dubois, S.; Hayward, S.; Koerner, T.B. Estimated Levels of Gluten Incidentally Present in a Canadian Gluten-Free Diet. Nutrients 2014, 6, 881-896. [CrossRef] [PubMed]

22. Mudryj, A.N.; Yu, N.; Aukema, H.M. Nutritional and health benefits of pulses. Appl. Physiol. Nutr. Metab. 2014, 39, 1197-1204. [CrossRef] [PubMed]

(C) 2017 by the authors; licensee MDPI, Basel, Switzerland. This article is an open access article distributed under the terms and conditions of the Creative Commons Attribution (CC BY) license (http:/ / creativecommons.org/licenses/by/4.0/). 